\title{
Rijit Kifoskolyozlu Hastalarda Uygulanan Halo Gravite Traksiyonun Yaşam Kalitesi Üzerine Etkisinin Değerlendirilmesi
}

\section{Evaluation of the Effect of Halo Gravity Traction on Quality of Life in Patients with Rigid Kyphoscoliosis}

\author{
Kemal Paksoy ${ }^{*}$ \\ ${ }^{1}$ İstanbul Bahçelievler Memorial Hastanesi, Nöroşirürji Departmanı, İstanbul, Türkiye \\ e-mail: drkemalpaksoy@hotmail.com \\ ORCID: 0000-0002-7677-7356 \\ *Sorumlu yazar/ Corresponding Author: Kemal Paksoy \\ Gönderim Tarihi / Received: 26.10.2020 \\ Kabul Tarihi / Accepted: 04.11.2020 \\ DOI: $10.34087 /$ cbusbed. 816636 \\ $\ddot{O} \mathbf{z}$
}

Giriş ve Amaç: Rijit kifoskolyoz hastalığının tedavisinde çözülmesi gereken birçok problem bulunur. Bu çalışmada amaç sorunların tedavisinde kullanılan halo gravite traksiyonu uygulanmasının hastalarda günlük yaşam aktivitelerine, fonksiyonlarına ve ruhsal durumlarına etkilerini ortaya koymaktı.

Gereç ve Yöntemler: Rijit kifoskolyoz tanısı ile cerrahisi yapılacak hastalara cerrahi öncesi halo gravite traksiyonu uygulandı. Çalışmamıza traksiyon tedavisi gören toplam 14 hasta alındı. Toplam 14 hastanın \%28,6'sı (n=4) erkek, $\% 71,4$ 'ü kadın $(\mathrm{n}=10)$ idi. Ortalama yaş $17.22 \pm 6.15$ idi. Hastaların 6'sı $(\% 42,8)$ idiyopatik skolyoz, 5'i $(\% 35,7)$ konjenital skolyoz ve 3'ü $(\% 21,5)$ nöromüsküler skolyozdu. Hastalara işlem sonrası 10'uncu gün ve traksiyon işlemi sonrası birinci ayda yaşam kalite ölçeklerinden Medical Outcome Study Short Form-36 (SF-36) ile değerlendirilmesi yapild1.

Bulgular: Halo traksiyon uygulamasının verilerinin analizi için Wilcoxon Signed Ranks Testi kullanıldı. İstatistiksel anlamlılık düzeyi $\mathrm{p}<0.05$ olarak belirlendi. Verilerin istatistik analiz sonucu fiziksel fonksiyon, sosyal işlev, fiziksel rol güçlüğü, emosyonel rol güçlüğü, ruhsal sağlık, enerji/canlılık/vitalite ve ağrı parametrelerindeki değişiklikler $p$ $<0.05$ olup anlamlıydı. Genel sağlık algısındaki değişiklikler ise istatistiksel anlamlı değildi.

Sonuç: Rijit kifoskolyoz olan hastalarda uygulanan halo gravite traksiyon yönteminin etkinliğinin yanında hastanın traksiyon süresi boyunca yaşam kalitesi üzerindeki olumlu etkisinin traksiyona adaptasyon süresi ile ilişkilidir. Günlük traksiyon eğitiminin ve bakımının bu adaptasyonda önemli olmaktadır. Hastaların uyku düzeni ve ağrı sorunlarının çözülmesi traksiyon süresince yaşam kalitesi üzerine pozitif yönde etkilidir.

Anahtar kelimeler: Halo yerçekimi traksiyonu, Rijit kifoskolyoz, Yaşam kalite ölçeği.

\section{Abstract}

ObjectiveThere are abundant problems have to be solved in the treatment of rigid kyphoscoliosis. The aim of this study was to reveal the effects of halo gravity traction application, which is used in the treatment of problems, on daily life activities, functions and mental states of patients.

Materials and Methods: Halo gravity traction was applied before their surgeries to patients who will undergo surgery with a diagnosis of rigid kyphoscoliosis. A total of 14 patients who received traction therapy were included in our study. $28.6 \%(n=4)$ of a total of 14 patients were male and $71.4 \%$ were female $(n=10)$. The mean age was $17.22 \pm$ 6.15. Six $(42.8 \%)$ of the patients were idiopathic scoliosis, $5(35.7 \%)$ congenital scoliosis and $3(21.5 \%)$ neuromuscular scoliosis. The patients were evaluated with the Medical Outcome Study Short Form-36 (SF-36), one of the quality of life scales, on the 10th day after the procedure and in the first month after the traction procedure.

Results: Wilcoxon Signed Ranks Test was used to analyze the data of the halo traction application. Statistical significance level was set at $\mathrm{p}<0.05$. As a result of statistical analysis of the data, changes in physical function, social function, physical role difficulty, emotional role difficulty, mental health, energy / stamina / vitality and pain parameters were $\mathrm{p}<0.05$ and were significant. The changes in the general health perception were not statistically significant. 
Conclusion: In addition to the effectiveness of the halo gravity traction method applied in patients with rigid kyphoscoliosis, its positive effect on the patient's quality of life during the traction period is related to the adaptation period to traction. Daily traction training and maintenance is important in this adaptation. Solving the pain and sleep pattern problems of the patients has a positive effect on the quality of life during traction.

Keywords: Halo gravity traction, Rigid kyphoscoliosis, Quality of life scale.

\section{Giriş}

İleri derece ve sert kifoskolyoz hastalıklarının tedavisi zorluklar içermektedir. Aynı zamanda yaşam kalitesini olumsuz etkilemekte ve tedavi edilmezse hastaların kardiyopulmoner fonksiyonlarını ciddi şekilde bozabilmektedir [1]. Hastaların deformitelerini düzeltebilmek için genelde osteotomi standart cerrahi teknik olarak kullanılmaktadır. Ancak sık kullanımına ve standart tedavi olmasına rağmen osteotomi uygulamaları omurilik yaralanması ve buna bağlı tam pleji içerebilen ciddi komplikasyonlara neden olabilir [2, 3]. Bu sorunlara çözüm sağlamak amaçlı halo gravite traksiyon (HGT) uygulaması yapılmaktadır. Cerrahiden önce planlanan traksiyon uygulaması sert eğriliklerin bir miktar düzeltilmesini sağlarken bu süreçte akut düzeltici manevraların kullanılmaması halo gravite traksiyonunun faydası olarak görülmüştür [4]. Böylece deformitede düzelme sağlarken nörolojik komplikasyon riskinide azaltmaktadır [5]. Ayrica halo gravite traksiyonunun solunum fonksiyonları üzerinde de olumlu etkileri bulunmaktadır [6].

Halo-gravite traksiyon uygulamasının faydaları bu şekilde olsada minimal invaziv olan bu işlemin baş ağrısı, bulantı, kusma, vida gevşemesi, enfeksiyon ve nörolojik defisitler gibi komplikasyonları literatürde bildirilmiştir [7].

Halo gravite traksiyonu ile ilgili literatürde birçok çalışma bulunmasına rağmen bildiğimiz kadarıyla uygulama yapılan hastalarda yaşam kalitesi ile ilgili bir çalışma bulunmamaktadır. Yaşam kalitesi anketleri, hastaların hissettiklerini, hastalığın günlük yaşam üzerindeki etkilerini kendi görüş açısı ile yansıtan subjektif değerlendirme yöntemleridir. Genel yaşam kalitesi ölçeklerinin en büyük avantajı, herkese uygulanabilir olması ve farklı medikal durumlarda hastalıkların karşılaştırılmasına olanak vermesidir. Bu çalışmada amacımız halo gravite traksiyonu uygulanan hastalarda günlük yaşam aktivitelerine, fonksiyonlarına ve ruhsal durumlarına etkilerini retrospektif ortaya koymakt1.

\section{Materyal ve Metot}

Çalışmamız İstanbul Bahçelievler Memorial Hastanesinde Ocak 2019- Mart 2020 tarihleri arasında ileri derecede ve sert kifoskolyoz tanısı konan hastalara cerrahi öncesi halo gravite traksiyonu uygulanması yapılan hastalar üzerine planlandı. Etik kurul aynı hastaneden alındı. İşlem öncesi bütün hastalardan onam alındı. Hastalara işlem sonrası 10'uncu gün ve traksiyon işlemi sonrası birinci ayda yaşam kalite ölçeklerinden Medical Outcome Study Short Form-36 (SF-36) ile değerlendirilmesi yapıldı. SF-36 değerlendirme ölçeği 8 alt parametreden oluşup toplam 36 madde bulunmaktadır. Fiziksel fonksiyon (10 madde), sosyal işlev (2 madde), fiziksel rol güçlüğü (4 madde), emosyonel rol güçlüğü (3 madde), ruhsal sağlık (5 madde), enerji/canlılık/vitalite (4 madde), ağrı (2 madde) ve genel sağlık algısı (5 madde) şeklinde alt parametrelerle değerlendirme yapılmaktadır[8]. Tablo 1 'de özetlenmiştir.

Her bir maddeye verilen cevapların puanlamaları kendi içinde hesaplanır ve 0-100 arasında değişen bir ölçeğe dönüştürülür. Düşük puan kötü sağlık durumunu ifade ederken yüksek puan daha iyi sağlık durumunu ifade etmektedir. Çalışmamızda ilk değerlendirilme süresinin onuncu gün seçilme nedeni hastalarda hedef ağırlığa ulaşıldığı zaman olduğu içindir.

\section{Seçilme kriterleri:}

1.Esnekliği \% $30^{\circ}$ 'nin altında olup koronal eğriliği $80^{\circ}$. $90^{\circ}$ 'nin üstünde ve sagital eğriliği $70^{\circ}$ 'nin üstünde olan hastalar

2.İlerleyici bir nörolojik defisiti olmayan hastalar

3.Akciğer problemleri ön planda olup solunum fonksiyon testlerinin ileri bozuk olan hastalar

Dışlama kriterleri:

1.Uyum sağlamada problem olma olasılığından dolayı 8 yaşından küçük olan hastalar

Tablo 1. Medical outcome study short form-36 alt parametreleri

\begin{tabular}{|l|l|l|}
\hline Alt parametreler & Madde & Maddeler \\
\hline Fiziksel fonksiyon & 10 & $3,4,5,6,7,8,9,10,11,12$ \\
\hline Fiziksel rol güçlüğü & 4 & $13,14,15,16$ \\
\hline Emosyonel rol güçlüğü & 3 & $17,18,19$ \\
\hline Enerji/canlılık/vitalite & 4 & $23,27,29,31$ \\
\hline Ruhsal sağlık & 5 & $24,25,26,28,30$ \\
\hline Sosyal işlev & 2 & 20,32 \\
\hline Ağrı & 2 & 21,22 \\
\hline Genel sağlık algısı & 5 & $1,33,34,35,36$ \\
\hline
\end{tabular}




\subsection{Halo Takma Prosedürü}

İşlem sedasyon altında yapıldığından hastalar işlem öncesi dört saatlik aç bırakıldı. Rutin anestezik hazırlıkları yapıldı. Ameliyathane ortamında steril işlemler sağlandıktan sonra sedasyon amaçlı midazolam $0,02 \mathrm{mg} / \mathrm{kg}$ ve fentanil $1 \mathrm{mcg} / \mathrm{kg}$ intravenöz yapıldı. Vida konacak yerleri \%10'luk povidon iyodin solüsyonu ile steril ettikten sonra \%2'lik lidokain $1 \mathrm{ml}$ ile lokal anestezi madde uygulandı. 4 adet vida yerleştirildi. İşlem sonrası her hastadan beyin tomografisi alındı. Hastalar işlem sonrası bir gün dinlendirildi. Başlangıç ağırlı̆̆ $5 \mathrm{~kg}$ olup günlük hasta tolerasyonuna göre $1-2 \mathrm{~kg}$ arası artırıldı. Hedef ağırlık normal ağırlığın \%30-50 arasında seçildi. Günlük nörolojik muayene ve ağrı durumları incelendi. Vidalar iki gün ara ile gevşeme olmaması için sıkıldı. Günlük vida cilt giriș yerleri \%10'luk povidon iyodin solüsyonu ile pansumanı yapıldı. Hastaların traksiyonda kalış süresi 12-16 saat arasında olduğundan mobilize, oturur pozisyonda ve yatak içerisinde traksiyonda kalabilecek şekilde cihaz ayarlaması yapıldı. Banyo, tuvalet ve uyku dişında hastalara traksiyon uygulamaları yapıldı. Traksiyon uygulanan hastanın görseli şekil 1 'dedir. Toplam traksiyon süresi 30-35 gün arası şeklinde planlandi.

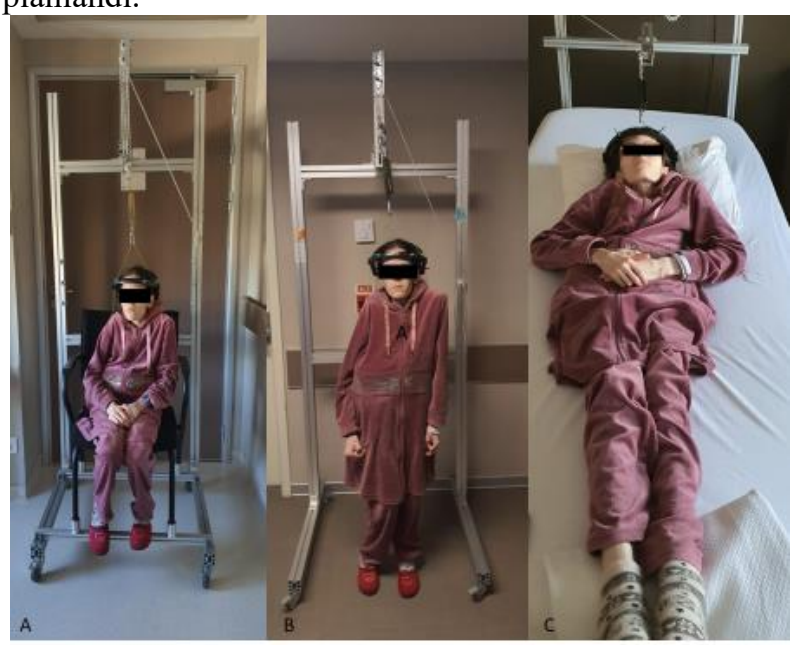

Şekil 1. Halo traksiyon uygulanan hasta

A. Oturuş pozisyonu, B. Ayakta duruş pozisyonu, C. Yatış pozisyonu

\section{2. Istatistiksel Metot}

Veriler halo traksiyon uygulamasının 10 'uncu günü ile traksiyon uygulaması sonrası yaşam kalite değerlendirilmesi SF 36 olarak sonuçları ayrı şekilde minimum, maximum, ortalama ve standart sapma olarak tablo 1'de verildi. Analiz için Wilcoxon Signed Ranks Testi kullanılmıştır. İstatistiksel analiz, cerrahi prosedürlere kör olan bağımsız bir istatistikçi tarafından yapıldı. İstatistiksel anlamlılık düzeyi $\mathrm{p}<0.05$ olarak belirlendi.

\section{Bulgular ve Tartışma}

Çalışmamıza HGT tedavisi gören toplam 14 hasta alındı. Toplam 14 hastanın \%28,6's1 (n=4) erkek, \%71,4'ü kadın $(\mathrm{n}=10)$ idi. Ortalama yaş $17.22 \pm 6.15$ idi.
Hastaların 6's1 (\%42,8) idiyopatik skolyoz, 5'i (\%35,7) konjenital skolyoz ve 3 'ü $(\% 21,5)$ nöromüsküler skolyozdu. Çalışmamızda 8 alt parametreler değerlendirildi. Halo gravite traksiyonunun onuncu günü fiziksel fonksiyon değerlendirilmesinde puanlama minimum: 10.0 maximum: 30.0 ortalama $21.786 \pm 6.3872$ iken traksiyonun birinci ayında puanlama minimum: 25.0 maximum: 85.0 ortalama: $45.357 \pm 20.5187$ idi. Halo traksiyonun onuncu günü ile traksiyonun birinci ayında fiziksel fonksiyon değişikliklerinin Wilcoxon Signed Ranks testi kullanılarak yapılan istatistik değerlendirmesinde $\mathrm{p}=0.001$ olup değişiklik anlamlıydı. Halo gravite traksiyonunun onuncu günü fiziksel rol güçlüğü değerlendirilmesinde puanlama minimum: 0 maximum: 75.0 ortalama $25.0 \pm 29.4174$ iken traksiyonun birinci ayında puanlama minimum: 25.0 maximum: 100.0 ortalama: $60.714 \pm 25.4087$ idi. Halo traksiyonun onuncu günü ile traksiyonun birinci ayında fiziksel rol güçlüğü değişikliklerinin Wilcoxon Signed Ranks testi kullanılarak yapılan istatistik değerlendirmesinde $\mathrm{p}=0.001$ olup değişiklik anlamlıydı. Halo gravite traksiyonunun onuncu günü emosyonel rol güçlüğü değerlendirilmesinde puanlama minimum: 0 maximum: 33.3 ortalama: $4.757 \pm 12.0924$ iken traksiyonun birinci ayında puanlama minimum: 0 maximum: 100.0 ortalama: $73.800 \pm 41.7142$ idi. Halo traksiyonun onuncu günü ile traksiyonun birinci ayında emosyonel rol güçlüğü değişikliklerinin Wilcoxon Signed Ranks testi kullanılarak yapılan istatistik değerlendirmesinde $\mathrm{p}=0.003$ olup değişiklik anlamlıydı. Halo gravite traksiyonunun onuncu günü enerji/canll1/k/vitalite değerlendirilmesinde puanlama minimum: 0 maximum: 35.0 ortalama: $15.714 \pm 13.9859$ iken traksiyonun birinci ayında puanlama minimum: 50.0 maximum: 75.0 ortalama: $64.286 \pm 9.1687$ idi. Halo traksiyonun onuncu günü ile traksiyonun birinci ayında enerji/canlılık/vitalite değişikliklerinin Wilcoxon Signed Ranks testi kullanılarak yapılan istatistik değerlendirmesinde $p=0.001$ olup değişiklik anlamlıydı. Halo gravite traksiyonunun onuncu günü ruhsal sağllk değerlendirilmesinde puanlama minimum: 4.0 maximum: 80.0 ortalama: $34.571 \pm 29.6692$ iken traksiyonun birinci ayında puanlama minimum: 52.0 maximum: 80.0 ortalama: $64.714 \pm 8.4346$ idi. Halo traksiyonun onuncu günü ile traksiyonun birinci ayında ruhsal sağlık değişikliklerinin Wilcoxon Signed Ranks testi kullanılarak yapılan istatistik değerlendirmesinde $\mathrm{p}=0.003$ olup değişiklik anlamlıydı. Halo gravite traksiyonunun onuncu günü sosyal işlev değerlendirilmesinde puanlama minimum: 0 maximum: 50.0 ortalama: $16.964 \pm 18.7385$ iken traksiyonun birinci ayında puanlama minimum: 50.0 maximum: 75.0 ortalama: $62.500 \pm 10.9632$ idi. Halo traksiyonun onuncu günü ile traksiyonun birinci ayında sosyal işlev değişikliklerinin Wilcoxon Signed Ranks testi kullanılarak yapılan istatistik değerlendirmesinde $\mathrm{p}=0.001$ olup değişiklik anlamlıydı. Halo gravite traksiyonunun onuncu günü ağrı değerlendirilmesinde puanlama minimum: 0 maximum: 45.0 ortalama: $12.679 \pm 15.2689$ iken traksiyonun birinci ayında 
puanlama minimum: 80.0 maximum: 90.0 ortalama: $84.286 \pm 5.1355$ idi. Halo traksiyonun onuncu günü ile traksiyonun birinci ayında ağrı değişikliklerinin Wilcoxon Signed Ranks testi kullanılarak yapilan istatistik değerlendirmesinde $\mathrm{p}=0.001$ olup değişiklik anlamlıydı. Halo gravite traksiyonunun onuncu günü genel sağlık algısı değerlendirilmesinde puanlama minimum: 0 maximum: 50.0 ortalama: $26.429 \pm 21.3474$ iken traksiyonun birinci ayında puanlama minimum: 25.0 maximum: 50.0 ortalama: $33.214 \pm 8.2292$ idi. Halo traksiyonun onuncu günü ile traksiyonun birinci ayında genel sağlık algısı değişikliklerinin Wilcoxon Signed Ranks testi kullanılarak yapılan istatistik değerlendirmesinde $\mathrm{p}=0.108$ olup değişiklik anlamlı değildi. İstatistiksel veriler Tablo 2 ve Tablo 3 'te özetlendirilmiştir.

Tablo 2. Yaşam kalite ölçek istatistiksel verileri

\begin{tabular}{|l|c|c|c|c|}
\hline & Min & Max & Mean & Std. Dvt \\
\hline Fiziksel Fonksiyonlar & 10,0 & 30,0 & 21,786 & 6,3872 \\
\hline Fiziksel Rol Güçlüğü &, 0 & 75,0 & 25,000 & 29,4174 \\
\hline Emosyonel Rol Güçlüğü &, 0 & 33,3 & 4,757 & 12,0924 \\
\hline Enerji/Canlıık &, 0 & 35,0 & 15,714 & 13,9859 \\
\hline Ruhsal Sağlık & 4,0 & 80,0 & 34,571 & 29,6692 \\
\hline Sosyal İşlev &, 0 & 50,0 & 16,964 & 18,7385 \\
\hline Ăgrı &, 0 & 45,0 & 12,679 & 15,2689 \\
\hline Genel Sağlık Algısı &, 0 & 50,0 & 26,429 & 21,3423 \\
\hline Fiziksel Fonksiyonlar(HS) & 25,0 & 85,0 & 45,357 & 20,5187 \\
\hline Fiziksel Rol Güçlüğü(HS) & 25,0 & 100,0 & 60,714 & 25,4087 \\
\hline Emosyonel Rol Güçlüğü (HS) &, 0 & 100,0 & 73,800 & 41,7142 \\
\hline Enerji/Canlılık(HS) & 50,0 & 75,0 & 64,286 & 9,1687 \\
\hline Ruhsal Sağlık(HS) & 52,0 & 80,0 & 64,714 & 8,4346 \\
\hline Sosyal İşlev(HS) & 50,0 & 75,0 & 62,500 & 10,9632 \\
\hline Ağrı(HS) & 80,0 & 90,0 & 84,286 & 5,1355 \\
\hline Genel Sağlık Algısı(HS) & 25,0 & 50,0 & 33,214 & 8,2292 \\
\hline Valid N (listwise) & & & & \\
\hline
\end{tabular}

Min: Minimum, Max: Maximum, Std. Dvt: Standart Deviation, HS: Halo traksiyon sonrası

Tablo 3. İstatistiksel sonuçlar

\begin{tabular}{|l|c|c|}
\hline & $\mathbf{Z}$ & Asymp. Sig. (2-tailed) \\
\hline Fiziksel Fonksiyonlar(HS) - Fiziksel Fonksiyonlar & $-3,322^{\mathrm{b}}$ &, 001 \\
\hline Fiziksel Rol Güçlüğü(HS) - Fiziksel Rol Güçlüğü & $-3,256^{\mathrm{b}}$ &, 001 \\
\hline Emosyonel Rol Güçlüğü(HS) - Emosyonel Rol Güçlüğü & $-3,022^{\mathrm{b}}$ &, 003 \\
\hline Enerji/Canlılık/Vitalite(HS) - Enerji/Canlılık/Vitalite & $-3,329^{\mathrm{b}}$ &, 001 \\
\hline Ruhsal Sağlık(HS) - Ruhsal Sağlık & $-2,696^{\mathrm{b}}$ &, 003 \\
\hline Sosyal İşlev(HS) - Sosyal İşlev & $-3,311^{\mathrm{b}}$ &, 001 \\
\hline Ağrı(HS) - Ağrı & $-3,327^{\mathrm{b}}$ &, 001 \\
\hline Genel Sağlık Algısı(HS) - Genel Sağlık Algısı & $-1,606^{\mathrm{b}}$ &, 108 \\
\hline
\end{tabular}
a. Wilcoxon Signed Ranks Test
b. Based on negative ranks. 


\subsection{Tartışma}

Sert ve ileri kifoskolyoz tedavisi zor ve sıkıntılar içeren ve bir çok sistemi ilgilendiren bir deformite hastalığıdır. $\mathrm{Bu}$ karmaşık sorunu çözmede cerraha fayda sağlayabilecek yardımcı yöntemlerden biri de halo gravite traksiyonudur. Halo gravite traksiyonu hastanın ağırlığına karşı kullanılan kontrollü uygulanan kuvvettir [9]. Rijit kifoskolyoz cerrahilerde en önemli komplikasyonlardan biri nörolojik defisitlerdir. Cerrahide ani düzeltme manevralarında omuriliğin aşırı distraksiyonu veya sıkışması nörolojik defisitleri tetikleyebilir. Halo gravite traksiyonun en büyük avantajı uzun süreli kontrollü traksiyon ile keskin açılı ve sert olan yerlerde kısmı iyileşme sağlayarak cerrahi esnada oluşabilecek nörolojik hasarlanmaları azaltabilmektedir [10]. Sert ve ileri kifoskolyozlu hastalarda diğer önemli sorunsa kardiopulmoner problemlerdir. Solunum fonksiyon testlerinin bozuk oluşu cerrahi süreyi ve stratejiyi etkileyen bir faktördür. Halo gravite traksiyon yönteminin bir diğer faydası ise k1sitlı solunum fonksiyonları üzerine artmış olumlu etkisi şeklindedir [11]. Radyolojik olarak halo traksiyon uygulamasının sagital ve koronal düzlemde eğrilikler üzerinde düzelmeler sağladığıyla ilgili bir çok literatürde çalışma bulunmaktadır [12, 13, 14]. Sponseller ve ark. yaptığ 1 bir çalışmada ise halo gravite traksiyon uygulamasının deformite üzerine radyolojik olarak düzeltme yönünde etkili olmadığını bildirmiştir [15]. Koller ve ark. ise halo traksiyonunun anterior veya posterior gevşetme cerrahileri yapılmadan eğrilikler üzerine etkili olamayacağını bildirmişlerdir [16]. Ancak literatürde genel yaklaşım halo traksiyonunun rijit kifoskloyozlu hastaların eğriliğine etkili bir yöntem olduğuyla ilgilidir. Etkili olan bu yöntemin bazı komplikasyonlarıda bulunmaktadır. Komplikasyonlar vida gevşemesi, vida giriş yerlerinde enfeksiyon, baş ağrısı, nörolojik defisit ve boyun ağrısı şeklinde klinik olarak karşılaşılmaktadır [17, 18]. Halo gravite traksiyonu ile ilgili literatürde traksiyon başlangıç ağırlık miktarı, ağırlık artış süresi, ağırlık artış miktarı ve hedef ağırlık ile traksiyonda kalış süresi konularında tam fikir birliği yoktur [19, 20, 21].

Bizim çalışmamızda başlangıç ağırlığımız ortalama beş kilo olup günlük 1-2 kg arası artış yaptık. Günlük nörolojik muayene ve klinik takip ile ağırlığı artırdık. Çalışmamızda herhangi bir nörolojik defist tespit etmedik. Özellikle ağırlık artışlarında hasta ile iyi uyumun ve klinik muayenenin bunda önemli olduğunu düşünmekteyiz. Halo traksiyonunda ilk on gün içerisinde en sık rastladığımız problem vida giriş yerlerindeki ağrıydı. Bunun için mutlaka hastalara analjezik tedavisi verildi. $\mathrm{Bu}$ dönemde başlangıç yaşam kalite değerlendirme ölçeğindeki ağrı puanlamasının yüksek oluşuna sebep oldu. Uygun analjezik tedavi sonrasındaki ağrı puanlamasının değerlendirmelerde ağrının azalması ya da hiç olmamasını sağladı. Adaptasyon ve halo traksiyona alışmasınında bu değerlerin olumlu düzelmesine etkisi olduğunu düşünmekteyiz. Başlangıç döneminde halo traksiyonu takılan hastaların uyku kalitesi ve süresinin bozulmalarına bağlı olarak oluştuğunu düşündüğümüz anksiyete bozuklukları mevcuttu. Bu süreçte psikiyatri desteği ve uyku düzeninin sağlanması ruhsal değerlendirmenin traksiyon sonrası ikinci haftadan itibaren olumlu yönde değiştiğini gözlemledik. Halo traksiyonu uygulanan bütün hastalarımıza mobilizasyon için başlangıçta eğitim verildi. Kontrolümüz altında günlük yürüyüş, oturma ve traksiyonla yatakta yatışları yapıldı. Bu şekilde halo traksiyonu günlük kullanma alışkanlığını hızlıca hastalara kazandırdığımızı düşünmekteyiz. Ayrıca başlangıçta değerlendirmenin olumsuz olduğu fiziksel fonksiyonlar, fiziksel rol güçlüğü ve sosyal işlevler alt başlıklarınında sonrası olumlu şekildeki değişikliğini bu şekilde yorumlayabiliriz. Hem adaptasyon sağlanması hem ağrının azalması hem de uyku düzeninin normale dönmesi hastalarda yaşam kalite değerlendirme ölçeğinin olumlu şekilde düzelmesini sağladığını düşünmekteyiz. Çalışmamızda hasta sayısının daha fazla olması gerektiğini ve bunun çalışmamız için bir kısıtlayıcı yön olduğunu düşünmekteyiz. Aynı zamanda sadece halo tarksiyonu uygulanan hasta grubu ile gevşetme sonrası halo traksiyonu uygulana grubun değerlendirmeside ayrı bir çalışma olarak düşünülebilir.

\section{Sonuç}

Rijit ve ileri kifoskolyoz olan hastalarda uygulanan halo gravite traksiyon yönteminin etkinliğinin yanında hastanın traksiyon süresi boyunca yaşam kalitesi üzerindeki olumlu etkisinin traksiyona adaptasyon süresi ile ilişkilidir. Günlük traksiyon eğitiminin ve bakımının bu adaptasyonda önemli olmaktadır. Hastaların uyku düzeni ve ağrı sorunlarının çözülmesi traksiyon süresince yaşam kalitesi üzerine pozitif yönde etkilidir.

\section{Referanslar}

1. Shimode, M, Kojima, T, Sowa, K, Spinal wedge osteotomy by a single posterior approach for correction of severe and rigid kyphosis or kyphoscoliosis, Spine, 2002, 27(20), 2260-2267.

2. Ponte, A, Orlando, G, Siccardi, G.L, The true Ponte osteotomy: by the one who developed it, Spine deformity, 2018, 6(1), 2-11.

3. Lenke, L.G, Sides, B.A, Koester, L.A, Hensley, M, Blanke, K.M, Vertebral column resection for the treatment of severe spinal deformity, Clinical Orthopaedics and Related Research, 2010, 468(3), 687-699.

4. Garabekyan, T, Hosseinzadeh, P, Iwinski, H.J, et al., The results of preoperative halo-gravity traction in children with severe spinal deformity, Journal of Pediatric Orthopaedics B, 2014, 23(1), 1-5.

5. Yang, C, Wang, H, Zheng, Z, Zhang, Z, Wang, J, Liu, H, Kim, YJ, Cho, S, Halo-gravity traction in the treatment of severe spinal deformity: a systematic review and meta-analysis, European Spine Journal, 2017, 26(7), 1810-1816.

6. Smiljanic, I, Kovac, V, Cimic, M, Changes in pulmonary functional parameters after surgical treatment of idiopathic scoliosis, Collegium Antropologicum, 2009, 33(Suppl 2), 145-52.

7. Bogunovic, L, Lenke, L.G, Bridwell, K.H, Luhmann, S.J, Preoperative halo-gravity traction for severe pediatric spinal deformity: Complications, radiographic correction and changes in pulmonary function, Spine Deformity, 2013, 1(1), 33-39.

8. Ware, J.E, Jr., Sherbourne, C.D, The MOS 36-Item Short-Form Health Survey (SF-36): I, Conceptual Framework and Item Selection, Medical Care, 1992, 30, 473-483.

9. Sink, E.L, Karol, L.A, Sanders, J, Birch, J.G, Johnston, C.E, Herring, J.A, Efficacy of perioperative halo-gravity traction in the treatment of severe scoliosis in children, Journal of Pediatric Orthopaedics B, 2001, 21(4), 519-524.

10. Zhang, H.Q, Gao, Q.L, Ge, L, et al., Strong halo-femoral traction with wide posterior spinal release and three dimensional spinal correction 
for the treatment of severe adolescent idiopathic scoliosis, Chinese Medical Journal, 2012, 125(7), 1297-302.

11. Bao, H, Yan, P, Bao, M, et al., Halo-gravity traction combined with assisted ventilation: an effective pre-operative management for severe adult scoliosis complicated with respiratory dysfunction, European Spine Journal, 2016, 25(8), 2416-2422.

12. Janus, G.J, Finidori, G, Engelbert, R.H, Pouliquen, M, Pruijs, J.E Operative treatment of severe scoliosis in osteogenesis imperfecta: results of 20 patients after halo traction and posterior spondylodesis with instrumentation, European Spine Journal, 2000, 9, 486-491.

13. Bouchoucha, S, Khelifi, A, Saied, W, Ammar, C, Nessib, M.N, Ben, Ghachem M, Progressive correction of severe spinal deformities with halo-gravity traction, Acta Orthopaedica Belgica, 2011, 77, 529-534.

14. Nemani, V.M, Kim, H.J, Bjerke-Kroll, B.T, Yagi, M, Sacramento, C, Akoto, H, et al., Preoperative halo-gravity traction for severe spinal deformities at an SRS-GOP site in West Africa: protocols, complications, and results, Spine (Phila Pa 1976), 2015, 40, 153161

15. Sponseller, P.D, Takenaga, R.K, Newton, P, Boachie, O, Flynn, J, Letko, L, et al., The use of traction in the treatment of severe spinal deformity, Spine (Phila Pa 1976), 2008, 33, 2305-2309.

16. Koller, H, Zenner, J, Gajic, V, et al., The impact of halo-gravity traction on curve rigidity and pulmonary function in the treatment of severe and rigid scoliosis and kyphoscoliosis: A clinical study and narrative review of the literature, European Spine Journal, 2012, 21(3), 514-29.

17. Saeed, M.U, Dacuycuy, M.A, Kennedy, D.J, Halo pin insertionassociated brain abscess: Case report and review of literature, Spine, 2007, 32(8), E271-74.

18. Garfin, S.R, Botte, M.J, Nickel, V.L, Complications in the use of the halo fixation device, Journal of Bone and Joint Surgery, 1987, 69(6), 954.

19. Xia, L, Li, P, Wang, D, Bao, D, Xu, J, Spinal osteotomy techniques in management of severe pediatric spinal deformity and analysis of postoperative complications, Spine (Phila Pa 1976), 2015, 40, E286E292.

20. Bumpass, D.B, Lenke, L.G, Bridwell, K.H, Stallbaumer, J.J, Kim, Y.J, Wallendorf, M.J, et al., Pulmonary function improvement after vertebral column resection for severe spinal deformity, Spine (Phila Pa 1976), 2014, 39, 587-595.

21. Park, D.K, Braaksma, B, Hammerberg, K.W, Sturm, P, The efficacy of preoperative halo-gravity traction in pediatric spinal deformity the effect of traction duration, Journal of Spinal Disorders \& Techniques, 2013, 26, 146-154.

http://edergi.cbu.edu.tr/ojs/index.php/cbusbed isimli yazarın CBU-SBED başlıklı eseri bu Creative Commons Alıntı-Gayriticari4.0 Uluslararası Lisansı ile lisanslanmıştır.

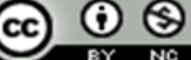

